
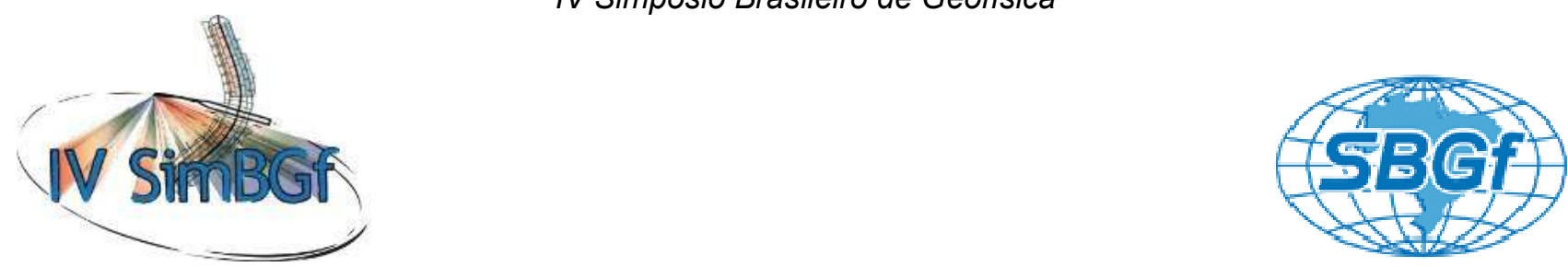

\title{
Perfilagem térmica e movimento de água em poços na cidade de Bebedouro/SP
}

${ }^{*}$ Rodrigo Corrêa Rangel e Yára Regina Marangoni, Instituto de Astronomia, Geofísica e Ciências Atmosféricas da Universidade de São Paulo (IAG/USP)

Copyright 2008, SBGf - Sociedade Brasileira de Geofísica

Este texto foi preparado para a apresentação no IV Simpósio Brasileiro de Geofísica, Belém, 14 a 17 de novembro de 2010. Seu conteúdo foi revisado pelo Comitê Técnico do IV SimBGf, mas não necessariamente representa a opinião da SBGf ou de seus associados. É proibida a reprodução total ou parcial deste material para propósitos comerciais sem prévia autorização da SBGf.

\section{Resumo}

Nas décadas de 70 e 80 alguns tremores de terra na Bacia do Paraná foram associados a poços profundos para exploração de água subterrânea. Desde 2004 tremores de terra vêm ocorrendo no município de Bebedouro/SP, onde os tremores estão concentrados nas proximidades, cerca de $1 \mathrm{~km}$, de poços profundos. Esses tremores têm acontecido de forma freqüente entre dezembro e meados de maio com pouco ou quase inexistente sismicidade entre julho e dezembro. Essa característica parece estar relacionada ao bombeamento de água nos poços para irrigação de lavoura na área na época de estiagem. Na região de Bebedouro afloram arenitos do Grupo Bauru (Formação Adamantina) com espessuras entre 50 e $120 \mathrm{~m}$. Abaixo dessa formação encontra-se o basalto da Formação Serra Geral. A região utiliza água subterrânea através de poços rasos ou profundos que buscam água no arenito ou nos aqüíferos das regiões fraturadas no basalto. Em 2005 foram feitas perfilagens de temperatura em 6 poços na área para determinar as possíveis entradas e saídas de água nos poços e verificar as conexões entre os aqüíferos do arenito e do basalto. Algumas dessas perfilagens foram refeitas em 2009 usando equipamento do IAG e do ON. O objetivo desde projeto é comparar as perfilagens térmicas feitas nos poços em 2005 e 2009, para verificar se o movimento de água nos poços está alterando o regime térmico local e determinar a velocidade do fluxo de água para as perfilagens realizadas em 2009.

\section{Introdução}

Perfilagens geotérmicas foram feitas na cidade de Bebedouro/SP ao se constatar indícios de uma correlação entre perfuração de poços tubulares profundos e a ocorrência de atividade sísmica a partir de 2004. Casos semelhantes de correlação entre perfuração de poços tubulares profundos e ocorrência de atividade sísmica ocorreram nas cidades de Nuporanga e Presidente Prudente (Yamabe \& Hamza, 1996), ambas na Bacia do Paraná nas décadas de 1980 e 1990.

As perfurações que atravessam as camadas confinantes podem atuar como condutos de infiltração das águas superficiais para os aqüíferos mais profundos, ou propiciar também a infiltração de água em fratura ou fendas do basalto. Essa infiltração pode causar sismos e também contaminação dos aqüíferos mais profundos. Investigações geotérmicas podem ser utilizadas no entendimento da natureza de movimentos de fluidos associados com sismos superficiais. $\mathrm{O}$ método geotérmico tem a vantagem de identificar as movimentações de água subterrânea através de medições simples de temperatura dentro do poço. $O$ enfoque principal deste trabalho é a identificação do movimento de água subterrânea, com base nas perfilagens térmicas de poços tubulares na região de Bebedouro/SP.

A idéia de usar o perfil de temperatura de um poço para estudo do movimento de fluidos foi desenvolvida na década de 1960. O assunto teve um breve ressurgimento na década de 1980 e houve pouco desenvolvimento posterior. Entretanto nos últimos anos existe uma nova tentativa de uso da técnica, como pode ser visto no artigo de revisão de Anderson (2005). Stallman (1960) mostrou as equações básicas para a transferência simultânea de calor e água no subsolo e sugeriu que as medições de temperatura em poços podem fornecer uma maneira de medir as taxas de circulação de águas subterrâneas. Trabalhos teóricos pioneiros na década de 1960 (Stallman 1965; Bredehoeft \& Papadopulos 1965) mostraram que a medição de temperatura poderia ser usada em soluções analíticas na forma unidimensional da equação de transporte de calor para estimar a velocidade de água. Bredehoeft \& Papadopulos (1965) desenvolveram curvas típicas com base na equação de Stallman (1960) para determinar o fluxo unidimensional de águas subterrâneas através de um ajuste de dados de temperatura em poços. Gráficos adimensionais de temperatura em função da profundidade podem ser combinados com as curvas de Bredehoeft e Papadopulos (1965) para obter soluções para as velocidades verticais de águas subterrâneas se a condutividade térmica do complexo sólido-líquido for conhecida ou estimada. Onde as temperaturas em poços estão em equilíbrio com o aqüífero ou aquitardo, é possível determinar o fluxo vertical das águas subterrâneas através de perfis térmicos. Melhorias feitas por Stallman (1967), Sorey (1971), Cartwright (1979), Boyle e Saleem (1979), e Taniguchi (1993) confirmaram que o deslocamento vertical de águas subterrâneas transporta calor por advecção e provoca a curvatura do perfil térmico dos primeiros quilômetros da crosta superior. A utilização pioneira de medições de temperatura à escala de bacia foi feita por Cartwright (1970) que usou o modelo de Bredehoeft \& Papadopulos (1965) para calcular a descarga de água subterrânea na Bacia de Illinois. Trabalhos posteriores usando soluções analíticas 
aplicadas a bacias sedimentares foram realizados principalmente por pesquisadores no Japão (Sakura 1993; Inagaki e Taniguchi 1994; Taniguchi 1993, 1994). Adicionalmente Lu e Ge (1996) apresentaram um método para avaliar o efeito da temperatura no fluxo de águas subterrâneas em camadas horizontais semi-confinadas.

Este trabalho tem por objetivo utilizar os dados das perfilagens térmicas para estimar a velocidade do fluxo da água subterrânea nos poços. Também iremos testar o equipamento de perfilagem térmica montado no Laboratório do IAG/USP comparando os resultados deste equipamento com os resultados obtidos com um equipamento comercial do Observatório Nacional (ON).

\section{Metodologia}

Dentro de um poço mede-se a temperatura a intervalos espaçados de profundidade para posterior cálculo do gradiente de temperatura e fluxo de calor.

O gradiente geotérmico $(\Delta T / \Delta z)$ é determinado por ajuste linear de dados de temperatura em um determinado intervalo de profundidade, considerando que a região esteja em estado estacionário. A densidade de fluxo de calor (q), ou fluxo geotérmico, é calculada pela relação:

$$
q=k \frac{\Delta T}{\Delta z}
$$

onde $k$ é a condutividade térmica do material. A condutividade térmica deve ser medida em laboratório ou pode ser obtida através de dados disponíveis na literatura.

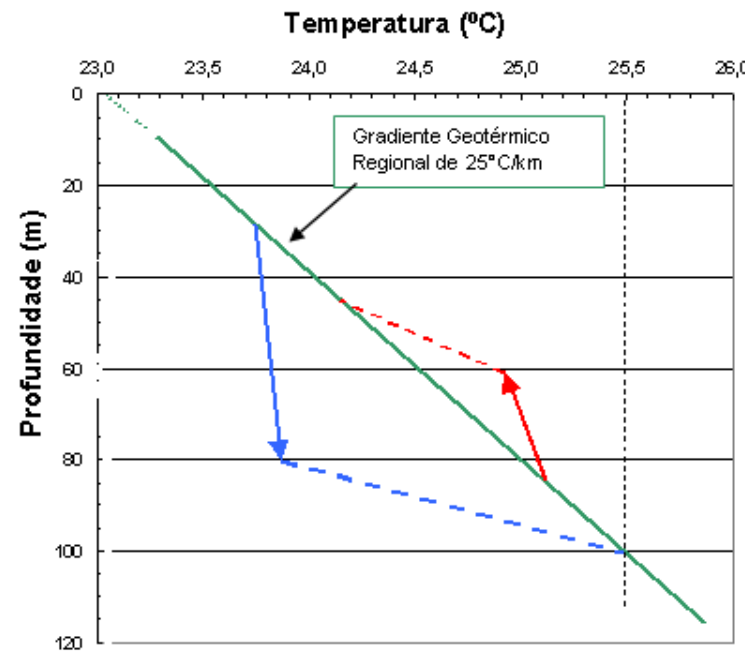

Figura 1 - Variação da temperatura com a profundidade, considerando um gradiente térmico de $25^{\circ} \mathrm{C} / \mathrm{km}$ (modificado de Yamabe et al., 2006).

A equação unidimensional que descreve o fluxo de calor estacionário em uma região sujeita a um fluxo de fluido é dada por (Bredehoeft e Papadopulos, 1965):

$$
\frac{\partial^{2} T}{\partial z^{2}}-\frac{c_{0} \rho_{0} v_{z}}{k} \frac{\partial T}{\partial t}=0
$$

onde $c_{o}$ é calor específico do fluido, $\rho_{o}$ a densidade do fluido, $\mathrm{k}$ é condutividade térmica do material saturado com fluido, e $\mathrm{U}_{\mathrm{z}}$ é a componente de velocidade do fluido na direção z, sendo z positivo para baixo.

Considerando fluxos verticais de água subterrânea e calor, num aqüífero confinado de dimensão $L$, a equação acima tem a seguinte solução:

$$
T(z)=\left(T_{L}-T_{0}\right)\left[\frac{e^{\beta z / L}-1}{e^{\beta}-1}\right]+T_{0}
$$

onde $T(z)$ é a temperatura a uma profundidade $z$, dentro do intervalo $L, T_{0}$ é a temperatura em $z=0$ e $T_{L}$ a temperatura em $z=L$. L é o intervalo de profundidade dentro do qual a velocidade do fluxo de água é constante e $\beta=\frac{c \rho L}{k} v_{z}$ é um parâmetro adimensional que é positivo ou negativo dependendo da direção do fluxo de água.

Se o movimento de água for para baixo (linha azul da Figura 1 , temos que $\beta>0$ e a temperatura, em uma determinada profundidade do poço dentro do intervalo de ocorrência do movimento descendente de água, será menor do que a temperatura na ausência do fluxo. Se o movimento de água for para cima (linha vermelha da Figura $1, \beta<0$ e as temperaturas observadas no intervalo de profundidade com movimento ascendente de água serão maiores do que as temperaturas na ausência do fluxo. A linha verde na Figura 1 representa o valor médio do gradiente geotérmico para a Bacia do Paraná (entre $20^{\circ} \mathrm{C}$ e $30^{\circ} \mathrm{C} / \mathrm{km}$ ) (Hurter \& Polack, 1996).

Bredehoeft e Papadopulos (1965) propuseram um procedimento gráfico para calcular a velocidade da água subterrânea através de uma camada semiconfinada, onde "curvas típicas" são comparadas com curvas observadas.

Para se determinar a velocidade vertical de água subterrânea $\mathrm{U}_{\mathrm{z}}$, a partir das medidas de temperatura, o valor de $\beta$ é encontrado comparando-se, por superposição, os pontos $\left(T_{z^{-}} T_{0}\right) /\left(T_{L}-T_{0}\right)$ contra $z / L$ calculados, com as curvas teóricas. $O$ valor de $\beta$ é inferido a partir da curva teórica que melhor se ajustar aos valores medidos. Definido o valor de $\beta, \mathrm{u}_{z}$ é calculado da seguinte relação:

$$
v_{z}=\frac{k \beta}{c \rho L}
$$

Na Figura 2 temos as curvas típicas desenvolvidas por Bredehoeft e Papadopulos (1965), utilizadas para se determinar os valores de $\beta$. 


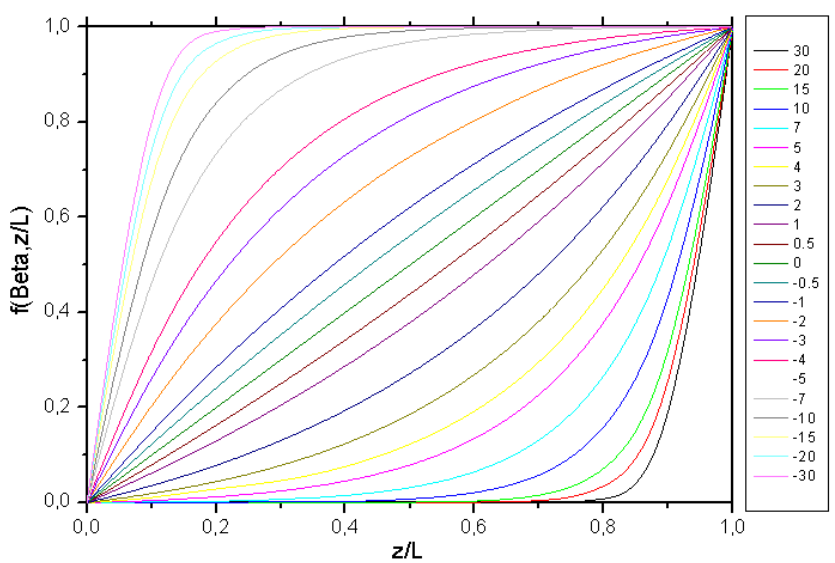

Figura 2 - Curvas típicas de $\mathrm{f}(\beta, \mathrm{z} / \mathrm{L})$ em função de $\mathrm{z} / \mathrm{L}$ desenvolvidas por Bredehoeft e Papadopulos (1965).

\section{Resultados}

\section{Calibração do perfilador do IAG}

A calibração do perfilador térmico do IAG foi feita em laboratório utilizando um banho termostático ultra estabilizado HAANE MK22, cuja temperatura foi precisamente medida por um termômetro de resistência de Platina (PT1000) e um voltímetro $4 \quad \frac{1}{2}$ dígitos. O termistor e o termômetro PT1000 foram mergulhados em um banho de água em que a temperatura foi variada continuamente de $16^{\circ} \mathrm{C}$ a $35^{\circ} \mathrm{C}$.

Tabela 1 - Dados da calibração do termistor.

\begin{tabular}{cc}
\hline Resistência $(\mathbf{O h m})$ & Temperatura $\left({ }^{\circ} \mathrm{C}\right)$ \\
\hline 7399,0 & 16,08 \\
6039,5 & 20,58 \\
4990,5 & 24,88 \\
3905,0 & 30,62 \\
3294,0 & 34,72 \\
\hline
\end{tabular}

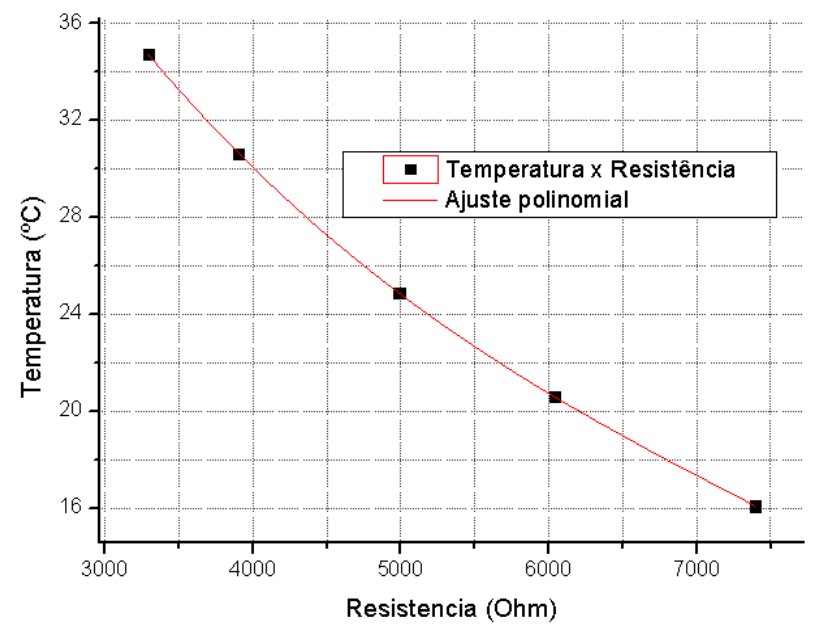

Figura 3 - Ajuste polinomial dos dados da calibração.
Os dados obtidos na calibração do termistor que foram utilizados para determinar a curva de calibração estão disponíveis na Tabela 1.

A curva de calibração do termistor foi obtida a partir de um ajuste polinomial dos dados da Tabela 1. A Figura 3 abaixo apresenta o gráfico obtido pelo ajuste polinomial e a equação (5) representa a relação da temperatura com a resistência elétrica obtida.

$T(R)=71,91649-0,01619 R+1,7419 \times 10^{-6} R^{2}-7,7528 \times 10^{-11} R^{3}$

(5)

\section{Perfilagens térmicas}

As ferfilagens térmicas foram efetuadas em cinco poços no Distrito de Andes do município de Bebedouro/SP e quatro poços no município de Monte Azul Paulista/SP. Foram realizadas três campanhas: setembro de 2005, fevereiro e agosto de 2009.

$\mathrm{Na}$ primeira campanha, em 2005, os dados foram tomados com um perfilador térmico do Observatório Nacional (ON) e as duas campanhas de 2009 foram feitas com um perfilador térmico desenvolvido pelo Prof. Dr. Francisco Yukio Hiodo do Laboratório de Instrumentação Geofísica do IAG/USP e pelo aluno Nilton Silva da Pós-Graduação (Hiodo et al., 2009). Em agosto de 2009 o ON também coletou dados nos poços com um equipamento novo, do qual não obtivemos informações sobre o funcionamento, por esse motivo os resultados obtidos pelo ON não foram utilizados nos cálculos de velocidade do fluxo de água. Os dados do ON serviram apenas para comparação com os dados obtidos com o perfilador do IAG.

Os casos de sismicidade induzida por poços tubulares em Nuporanga (Yamabe \& Hamza, 1996) e Presidente Prudente (Yamabe, 1999) estão relacionados com camadas de arenito entre derrames de basalto (intertrape). Em ambos os casos a infiltração de água dos poços em fraturas ou fendas do basalto, a partir das camadas intertrapes, propiciada pela perfuração dos poços, parece ter sido a origem dos sismos.

A perfilagem térmica consiste em introduzir uma sonda térmica no interior de um poço, conectada à extremidade de um cabo elétrico multi condutor. Dentro dessa sonda está um termistor, cuja variação da resistência elétrica com a temperatura é determinada na superfície através de um multímetro digital. Os perfiladores térmicos utilizados em 2005 e 2009 possuem uma precisão relativa de $\pm 0,005^{\circ} \mathrm{C}$. Isso permite identificação de pequenas variações de temperatura indicativas de entradas ou saídas de água no poço, através de fraturas, fendas ou de material alterado da rocha. As medições podem ser realizadas em quaisquer intervalos de profundidade. Convém notar que as operações de perfilagem térmica são viáveis somente em poços livres, ou seja, que não possuem tubulações ou bombas submersas instaladas.

Os dados e as análises dos dados das perfilagens térmicas realizadas em 2005 estão disponíveis em Yamabe et al. (2006). As perfilagens foram realizadas 
com um perfilador térmico pertencente ao Observatório Nacional (ON). As medições foram efetuadas em intervalos de dois metros, durante as operações de descida da sonda. As distribuições verticais de temperaturas estão dispostas na Figura 3 (Yamabe et al., 2006).

As perfilagens de fevereiro de 2009 foram realizadas entre os dias 12 e $14 \mathrm{com}$ o perfilador térmico do IAG. Dos poços perfilados em 2005, apenas os da Fazenda Santa Cruz estavam em condições de se fazer medidas, ou seja, os poços ainda encontravam-se sem bomba hidráulica instalada. Também estava disponível um novo poço na Fazenda Retiro em Monte Azul Paulista. Durante essa campanha, o índice de chuva foi alto, sendo que apenas no dia 13/02/2009 choveu mais do que $60 \mathrm{~mm}$. Contudo, mesmo com as chuvas intensas, foram realizadas perfilagens nos dois poços da Fazenda Santa Cruz e no poço da Fazenda Retiro. Na Figura 5 temos os perfilagens térmicas realizadas em fevereiro de 2009. No poço 2 da Fazenda Santa Cruz, não foi possível descer a sonda a uma profundidade maior do que $50 \mathrm{~m}$, como pode ser observado na Figura 5.

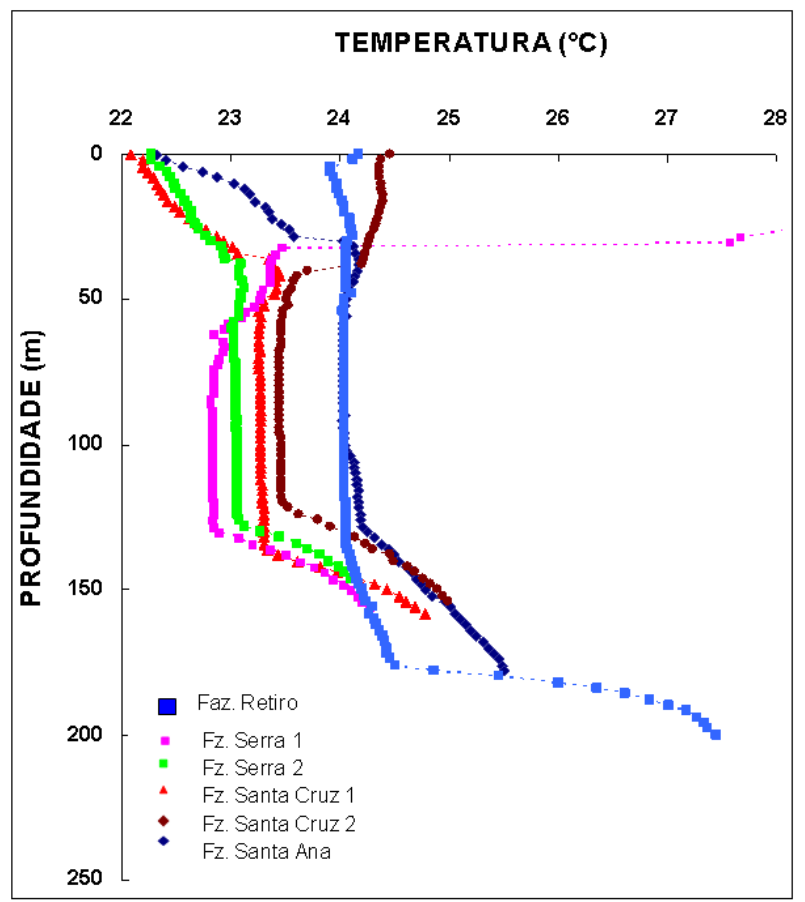

Figura 4 - Perfilagens térmicas realizadas em setembro de 2005 (Yamabe et al., 2006).

As perfilagens de agosto de 2009 foram realizadas entre os dias 10 e 12 com o perfilador térmico do IAG. O ON tomou medidas com um equipamento novo. Nesta campanha foram perfilados quatro poços: 2 poços na Fazenda Santa Cruz no Distrito de Andes na cidade de Bebedouro/SP e 2 poços na Fazenda São Pedro na cidade de Monte Azul Paulista. Os dois primeiros poços foram perfilados nas duas campanhas anteriores, em 2005 e fevereiro de 2009, já os outros dois poços foram perfilados pela primeira vez. As perfilagens realizadas pelo ON serviram para comparar com os dados obtidos com o perfilador desenvolvido no IAG. Na Figura 6 temos as perfilagens térmicas realizadas nesta campanha. A perfilagem de fevereiro de 2009 detectou obstrução deste poço. A proprietária da fazenda contratou manutenção que o desobstruiu. Com isso foi possível realizar a perfilagem completa nos $160 \mathrm{~m}$ originais do poço 2 .

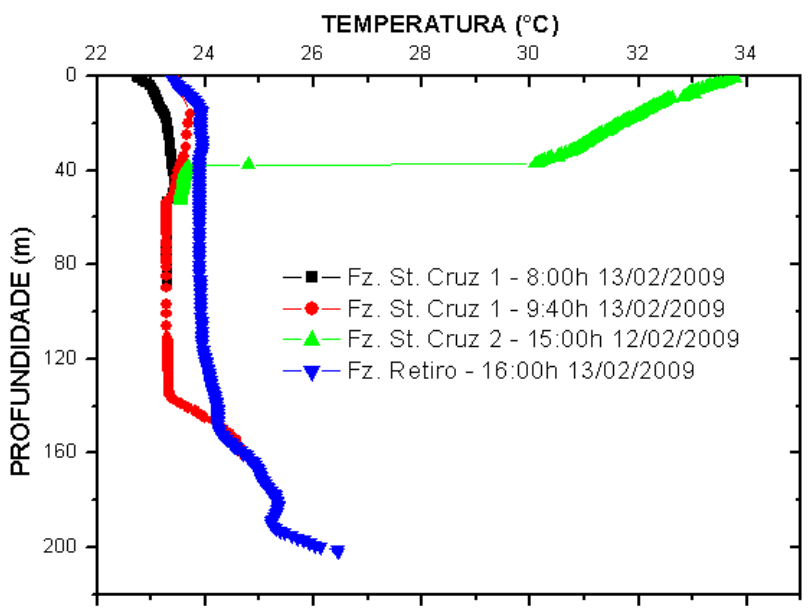

Figura 5 - Perfilagens térmicas realizadas em fevereiro de 2009.

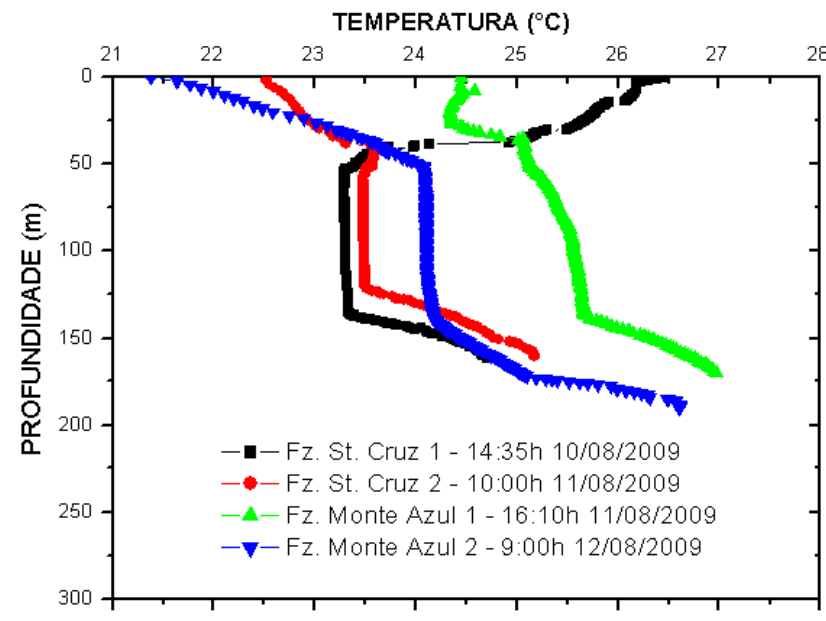

Figura 6 - Perfilagens térmicas realizadas em agosto de 2009.

\section{Velocidade de movimento da água}

O método da determinação da velocidade do movimento da água nos poços desenvolvido por Bredehoeft e Papadopulos (1965) foi aplicado para as perfilagens realizadas em fevereiro e agosto de 2009. Bredehoeft e Papadopulos (1965) propuseram um procedimento gráfico para calcular a velocidade da água subterrânea através de uma camada semiconfinada, onde "curvas típicas" de $\mathrm{f}(\beta, \mathrm{z} / \mathrm{L})=\frac{T_{z}-T_{0}}{T_{L}-T_{0}}=\left[\frac{e^{\beta z / L}-1}{e^{\beta}-1}\right]$ em função de $z / L$ ( $T_{z}$ é a temperatura a uma profundidade $z$, dentro do intervalo $L$ de profundidade, $T_{0}$ é a temperatura em $z=$ 0 e $T_{L}$ a temperatura em $z=L$ ) são comparadas com curvas observadas para se determinar o valor de $\beta$. Na 
Figura 2 têm-se as curvas típicas desenvolvidas pelos autores.

Nas Tabelas 2 e 3 têm-se as velocidades do movimento da água em três intervalos: 1) arenito com movimento de água, 2) basalto com movimento de água e 3) basalto com água saindo do poço. A velocidade de movimento da água foi determinada a partir da equação (4), onde $\mathrm{k}_{\text {arenito }}$ $=3,94 \pm 0,14 \mathrm{wm}^{-1} \mathrm{k}^{-1}$, $\mathrm{k}_{\text {basalto }}=1,86 \pm 0,10 \mathrm{wm}^{-1} \mathrm{k}^{-1}$, Carenito $=710 \mathrm{~J} / \mathrm{kg}^{\circ} \mathrm{C}, C_{\text {basalto }}=840 \mathrm{~J} / \mathrm{kg}^{\circ} \mathrm{C}$, Parenito $=2,35 \pm 0,02$ $\mathrm{g} / \mathrm{cm}^{3}$ e $\rho_{\text {basalto }}=2,98 \pm 0,02 \mathrm{~g} / \mathrm{cm}^{3}$.

Em ambas as Tabelas, os valores em parênteses na coluna dos Intervalos - $L$ representam o intervalo de profundidade. Os valores negativos de velocidade indicam que o movimento de água é para cima e os valores positivos de velocidade indicam que o movimento de água é para baixo, isso porque foi assumido um referencial para baixo na equação (2).

Tabela 2 - Velocidade do movimento de água para as perfilagens realizadas em fevereiro de 2009.

\begin{tabular}{cccc} 
& $\begin{array}{c}\text { Intervalos }-\mathbf{L} \\
(\mathbf{m})\end{array}$ & Beta & $\begin{array}{c}\text { Velocidade } \\
(\mathbf{m} / \mathbf{s})\end{array}$ \\
\hline Santa Cruz 1 & $54-89(35)$ & $-1,0$ & $-1,96 \times 10^{-8}$ \\
\hline Santa Cruz 2 & $38-53(15)$ & $-4,0$ & $-1,83 \times 10^{-7}$ \\
\hline \multirow{4}{*}{ Fz. Retiro } & $35-100(65)$ & 20,0 & $2,11 \times 10^{-6}$ \\
& $100-140(40)$ & 1,5 & $7,50 \times 10^{-8}$ \\
& $140-200(60)$ & 2,0 & $6,67 \times 10^{-8}$ \\
\hline
\end{tabular}

Tabela 3 - Velocidade do movimento de água para as perfilagens realizadas em agosto de 2009.

\begin{tabular}{cccc}
\hline & $\begin{array}{c}\text { Intervalos }-\mathbf{L} \\
(\mathbf{m})\end{array}$ & Beta & $\begin{array}{c}\text { Velocidade } \\
(\mathbf{m} / \mathbf{s})\end{array}$ \\
\hline & $54-104(50)$ & $-1,0$ & $-1,37 \times 10^{-8}$ \\
Santa Cruz 1 & $104-134(30)$ & $-0,5$ & $-3,33 \times 10^{-8}$ \\
& $134-160(26)$ & $-0,8$ & $-5,77 \times 10^{-8}$ \\
\hline & $55-105(50)$ & $-30,0$ & $-4,12 \times 10^{-7}$ \\
Santa Cruz 2 & $105-119(14)$ & $-5,0$ & $-7,14 \times 10^{-7}$ \\
& $119-160(41)$ & $-0,5$ & $-2,44 \times 10^{-8}$ \\
\hline & $40-48(8)$ & 0,5 & $4,29 \times 10^{-8}$ \\
Monte Azul 1 & $48-135(87)$ & $-2,5$ & $-5,75 \times 10^{-8}$ \\
& $135-170(35)$ & $-0,5$ & $-2,86 \times 10^{-8}$ \\
\hline & $52-100(48)$ & $-3,0$ & $-4,29 \times 10^{-8}$ \\
Monte Azul 2 & $100-140(40)$ & 3,5 & $1,75 \times 10^{-8}$ \\
& $140-188(48)$ & 2,0 & $8,33 \times 10^{-8}$ \\
\hline
\end{tabular}

\section{Discussão e Conclusões}

O poços da Fazenda Santa Cruz 1 e 2 foram perflados nas 3 campanhas, observa-se que as 3 perfilagens são coerentes.

As características dos perfis de temperatura indicam movimentação de água dentro dos poços em intervalos de profundidades geralmente entre 40 e $130 \mathrm{~m}$, aqui chamada de zona de temperatura constante (ZTC). Observa-se também que ocorrem geralmente saída de água dos poços em profundidades entre 120 e $180 \mathrm{~m}$, chamada de zona de temperatura alta (ZTA).

A análise dos perfis térmicos permitiram determinar as velocidades de movimento da água dentro dos poços. Da Tabela 2 observa-se que os poços da Fazenda Santa Cruz 1 e 2, perfilados em fevereiro de 2009, apresentam movimento de água para cima e o poço da Fazenda Retiro apresenta movimento de água para baixo. $\mathrm{E}$ da Tabela 3 observa-se que para os poços perfilados em agosto de 2009, os poços da Fazenda Santa Cruz 1 e 2 apresentam movimento de água para cima, o poço de Monte Azul 1 apresenta no primeiro intervalo (L) movimento de água para baixo e nos dois intervalos seguintes o movimento de água é para cima e, para o poço de Monte Azul 2, no primeiro intervalo (L) o movimento de água é para cima e nos dois intervalos seguintes o movimento de água é para baixo.

Apesar dos gradientes térmicos nas zonas de temperatura constante (ZTC) serem muito baixos $(<5$ ${ }^{\circ} \mathrm{C} / \mathrm{km}$ ), a velocidade do movimento de água dentro dos poços é baixo. Observa-se também que as zonas de temperatura alta (ZGA) apresentam gradiente térmico anômalo, apresentando valores maiores do que 100 ${ }^{\circ} \mathrm{C} / \mathrm{km}$.

As perfilagens térmicas indicam que a alteração no regime térmico, neste local, pode estar associada às atividades sísmicas. $\mathrm{O}$ mecanismo diretamente responsável pelas mudanças no regime térmico é o movimento de água dentro dos poços.

\section{Referências}

Anderson, M.P., 2005. Heat as a ground water tracer. Ground Water, 43(6): 951-968.

Assumpção, M. e Yamabe, T.H., 2005. Atividade Sísmica no Distrito de Andes, Bebedouro, e a Possível Relação com Perfuração de Poços Tubulares. (Relatório não publicado www.iag.usp.br/ marcelo/bebedouro ).

Assumpção, M., Yamabe, T.H. e Barbosa, J.R., 2008. Atividade sísmica na Bacia do Paraná induzida pela perfuração de poços tubulares profundos. XV Congresso Brasileiro da ABAS, Natal, CD-ROM.

Assumpção, M., Yamabe, T.H., Barbosa, J.R. e Hamza, V.M., 2009. Sismos induzidos por poços de água na Bacia do Paraná. Boletim SBGf, 1: 15-18.

Boyle, J.M. e Saleem. Z.A., 1979. Determination of recharge rates using temperature-depth profiles in wells. Water Resources Research 15, no. 6: 1616-1622.

Bredehoeft, J.D. e Papadopulos, I.S., 1965. Rates of vertical groundwater movement estimated from the Earth's thermal profile. Water Resources Research, 1(2): 325-328.

Cartwright, K., 1970. Groundwater discharge in the Illinois basin as suggested by temperature anomalies. Water Resources Research 6, no. 3: 912-918. 
Cartwright K., 1979. Measurement of fluid velocity using temperature profiles: Experimental verification. Journal of Hydrology 43: 185-194.

Drury, M. J. e Jessop, A. M., 1982. The effect of a fluidfilled fracture on the temperature profile in a borehole. Geothermics , 145-152.

Feitosa, F.A.C. e Manoel $\mathrm{F}^{\circ}$, J. (Coords.)., 2000. Hidrogeologia - Conceitos e Aplicações. 2a ed., CPRM/REFO, LABHID-UFPE, Fortaleza, Brasil.

Hamza, V.M., 1982. Pesquisas de medições de temperatura subsuperficial: Importância para a hidrogeologia. Revista de Águas Subterrâneas, 5, 65-99.

Hurter, S. e Pollack, H., 1996. Terrestrial heat flow in the Paraná Basin, SE Brazil. Journal of Geophysycal Research 101 (84), 8659-8671.

Hiodo, F.Y., Morais, L.H., Silva, N. e Yamabe, T.H., 2009. A temperature logging system: development and application. Eleventh International Congress of the Brazilian Geophysical Society. Salvador, BA.

Inagaki, N., e M. Taniguchi., 1994. Estimations of hydraulic conductivity and groundwater flow systems by using groundwater temperature in Nara Basin, Japan. Journal of the Japanese Association of Hydrological Sciences 24, no. 3: 171-182.

Kappelmeyer, O. e Haenel, R., 1974. Geothermics with special reference to application. Geoexploration Monographs, Series $1-$ n. 4.

Lu, N., e S. Ge., 1996. Effect of horizontal heat and fluid flow on the vertical temperature distribution in a semiconfining layer. Water Resources Research $32, n^{\circ} 5$ : 1449-1453.

Mansure, A. J. e Reiter, M., 1979. Vertical groundwater movement correction for heat flow. Journal of Geophysycal Research 84, 3490 -3496.

Sakura, Y., 1993. Groundwater flow estimated from temperatures in the Yonezawa Basin, Northeast Japan. In Tracers in Hydrology, 161-170. IAHS Publication 215. Oxfordshire, UK: IAHS.

Sorey, M.L., 1971. Measurement of vertical ground-water velocity from temperature profiles in wells. Water Resources Research 7, no. 4: 963-970.

Stallman, R.W., 1960. Notes on the use of temperature data for computing groundwater velocity, Groundwater notes 39. U.S. Geological Survey, Washington, DC.

Stallman, R.W., 1965. Steady one-dimensional fluid flow in a semi-infinite porous medium with sinusoidal surface temperature. Journal of Geophysical Research 70, no. 12: 2821-2827.

Stallman, R.W., 1967. Flow in the zone of aeration. In: Chow VT (ed) Advances in Hydroscience. Academic Press, New York, pp 151-195.
Taniguchi, M., 1993. Evaluation of vertical groundwater fluxes and thermal properties of aquifers based on transient temperature-depth profiles. Water Resources Research 29, no. 7: 2021-2026.

Taniguchi, M., 1994. Estimated recharge rates from groundwater temperatures in the Nara Basin, Japan. Hydrogeology Journal 2, no. 4: 7-14.

Yamabe, T.H., 1999. Estudos geofísicos para explicar a sismicidade induzida e orientar a exploração de água subterrânea em Nuporanga-SP. Tese de Doutorado, Instituto de Astronomia, Geofísica e Ciências Atmosféricas, USP, São Paulo.

Yamabe, T.H. \& Hamza, V.M., 1996. Geothermal Investigation in an area of induced seismic activity, Northern São Paulo State, Brazil. Tectonophysics, 253, 209-225.

Yamabe, T.H. e Berrocal, J., 1991. A origem da atividade sísmica de Presidente Prudente (SP): induzida ou natural?. II Int. Soc. Bras. Geofísica, Salvador, Proceedings, vol. 2: 521-528.

Yamabe, T.H., Hamza, V.M., Assumpção, M.e Birelli, C.A., 2006. Movimentos de água subterrânea relacionados com a a atividade sísmica em Bebedouro (SP): inferências com geotermia. II Simpósio Brasileiro de Geofísica, Natal, CD-ROM. 